\title{
PAPER
}

\section{Bioinspired and sustainable chitosan-based monoliths for antibody capture and release}

Telma Barroso, Ana C. A. Roque* and Ana AguiarRicardo*

Chitosan-based monoliths activated by plasma technology induced the coupling of a biomimetic ligand and exhibited remarkable performance for the one-step capture and recovery of antibodies.

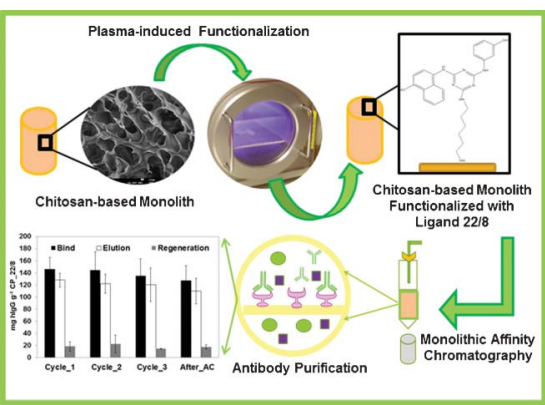

Please check this proof carefully. Our staff will not read it in detail after you have returned it.

Translation errors between word-processor files and typesetting systems can occur so the whole proof needs to be read. Please pay particular attention to: tabulated material; equations; numerical data; figures and graphics; and references. If you have not already indicated the corresponding author(s) please mark their name(s) with an asterisk. Please e-mail a list of corrections or the PDF with electronic notes attached — do not change the text within the PDF file or send a revised manuscript.

Please bear in mind that minor layout improvements, e.g. in line breaking, table widths and graphic placement, are routinely applied to the final version.

We will publish articles on the web as soon as possible after receiving your corrections; no late corrections will be made.

Please return your final corrections, where possible within $\mathbf{4 8}$ hours of receipt, by e-mail to: advances@rsc.org

Electronic (PDF) reprints will be provided free of charge to the corresponding author. Enquiries about purchasing paper reprints should be addressed via: http://www.rsc.org/publishing/journals/guidelines/paperreprints. Costs for reprints are below:

$\begin{array}{lrr}\text { Reprint costs } & & \\ \text { No of pages } & \text { Cost for } 50 \text { copies } & \text { Cost for each additional } 50 \text { copies } \\ 2-4 & £ 225 & £ 125 \\ 5-8 & £ 350 & £ 240 \\ 9-20 & £ 675 & £ 550 \\ 21-40 & £ 1250 & £ 975 \\ >40 & £ 1850 & £ 1550\end{array}$

Cost for including cover of journal issue:

$£ 55$ per 50 copies 


\section{Authors Queries}

Journal:

Paper: c2ra21687f

Title: Bioinspired and sustainable chitosan-based monoliths for antibody capture and release

Editor's queries are marked like this... 1, and for your convenience line numbers are indicated like this... 5.

\begin{tabular}{|l|l|l|}
\hline $\begin{array}{l}\text { Query } \\
\text { Reference }\end{array}$ & Query & Remarks \\
\hline 1 & $\begin{array}{l}\text { [INFO-1] Please carefully check the spelling of all } \\
\text { author names. This is important for the correct } \\
\text { indexing and future citation of your article. No late } \\
\text { corrections can be made. FOR YOUR } \\
\text { INFORMATION: You can cite this paper before the } \\
\text { page numbers are assigned with: (authors), RSC Adv., } \\
\text { DOI: 10.1039/c2ra21687f. }\end{array}$ & \\
\hline 2 & $\begin{array}{l}\text { Please indicate where ref. 30 should be cited in the } \\
\text { text. }\end{array}$ & \\
\hline
\end{tabular}




\title{
Bioinspired and sustainable chitosan-based monoliths for antibody capture and release
}

\author{
Telma Barroso, Ana C. A. Roque* and Ana Aguiar-Ricardo*
}

Received 3rd August 2012, Accepted 18th September 2012

DOI: $10.1039 / \mathrm{c} 2 \mathrm{ra21687f}$

Chitosan-based monoliths activated by plasma technology induced the coupling of a robust

biomimetic ligand, previously reported as an artificial Protein A, with high yields while minimizing the environmental impact of the procedure. Due to the high porosity, good mechanical and tunable physicochemical properties of the affinity chitosan-based monoliths, it is possible to achieve high

20 binding capacities ( $150 \pm 10 \mathrm{mg}$ antibody per gram support), and to recover $90 \pm 5 \%$ of the bound protein with $98 \%$ purity directly from cell-culture extracts. Therefore, the chitosan-based monoliths prepared by clean processes exhibit a remarkable performance for the one-step capture and recovery of pure antibodies or other biological molecules with biopharmaceutical relevance.

\section{Introduction}

Antibody-based biopharmaceuticals will be a major source of new therapies for at least the next 10 years. ${ }^{1}$ The large number of antibody products in development certainly supports the case for optimized antibody manufacturing approaches. However, the large quantities in which some antibody products are required put considerable pressure on current manufacturing facilities. ${ }^{2,3}$ In particular, current purification processes are struggling to equal the high productivities already obtained in upstream antibody production. Affinity chromatography using Protein A from Staphylococcus aureus is the method of choice for antibody capture during the purification process. ${ }^{1}$ However, protein A resins utilized in chromatography are expensive adsorbents with low stability, often causing the leaching of the affinity ligand 40 together with the antibody product. ${ }^{1,2,4}$ Thus, synthetic affinity ligands mimicking biological receptors have been developed in an attempt to overcome Protein A drawbacks. ${ }^{5}$ Ligands based on a triazine scaffold, in particular ligand $22 / 8$ or artificial protein A, and are known to be low cost and highly resistant to the harsh conditions employed during cleaning-in-place (CIP) and sterilization-in-place (SIP) ${ }^{5,6}$ Ligand $22 / 8$ has been immobilized on agarose, ${ }^{5}$ cellulose membranes, ${ }^{7}$ and magnetic particles, $^{8}$ and shown to selectively bind to human Immunoglobulin $\mathrm{G}$ (hIgG) when employed in chromatographic processes. With the need to treat large volumes of concentrated antibody solutions, fast processes with high selectivity are desired. ${ }^{9,10}$ Monoliths are porous materials cast in a single block and inserted into a chromatography housing. These porous supports have been successfully employed in the purification of biological species. ${ }^{11-14}$ As convective transport is prevalent when using monoliths, faster volumetric throughput rates are achieved thus increasing the process speed and productivity. ${ }^{9}$

The aim of this work was to combine the robustness of synthetic affinity ligands, namely ligand 22/8, with monolith blocks prepared from biopolymeric materials, in particular chitosan (CHT). In addition, sustainable chemistry options have been adopted for the preparation and functionalization of the materials based on freeze-drying method ${ }^{15,16}$ and plasma technology, ${ }^{17,18}$ respectively. In particular, freeze drying processes work by freezing the casting solution and then reducing the surrounding pressure to allow the frozen water in the material to sublimate directly from the solid phase to the gas phase, resulting in attractive porous structures. ${ }^{19}$ On the other hand, plasma technology is a fast and solvent free technique which allows surface modification through the introduction of chemical species. ${ }^{17-20}$ Recently, plasma surface activation was combined for the first time with supercritical fluid technology to surface-graft stimuli-responsive hydrogels on differently shaped devices. $^{21}$ Herein, plasma surface activation was extended to introduce radicals on monolith surfaces for further coupling with the affinity ligand. The materials produced have been characterized in terms of morphological, mechanical and physicochemical properties, and have shown to recover antibodies directly from crude cell samples. Chitosan (CHT) has been selected due to its nontoxic, antimicrobial, biocompatible, and biodegradable properties, as well as its $\mathrm{pH}$ sensitive behavior. ${ }^{22}$ Owing to a high molecular weight, chitosan forms viscous solutions in dilute aqueous acetic acid that can be used to produce porous structures. The tensile strength of these structures can be improved through crosslinking with epichlorohydrin $^{23}$ or glutaraldehyde, ${ }^{24}$ copolymerization with other monomers, or via blending. In this work chitosan was copolymerized (cryo-polymerization) with glycidyl methacrylate (GMA) at low temperatures in order to produce well defined porous monoliths with good tensile strength. Poly(vinyl alcohol) 
(PVA) was also blended with chitosan as another alternative strategy to improve the mechanical performance of chitosan monoliths. The processing of these renewable materials into 3D structures with tunable and controlled morphological and mechanical properties, large surface area and their subsequent functionalization with a low cost affinity ligand through green methodologies will offer a great contribution in materials design for bioseparation processes. This integrated process aims to replace traditional practices of monolith preparation and 10 functionalization by new ones where the integrity of the support is maintained from its conception to its application even at industrial scale.

\section{Results and discussion}

\subsection{Preparation and characterization of native chitosan-based monoliths}

Supports for protein separation must ideally possess high hydrophilicity, chemical and mechanical resistance, a narrow pore size distribution, as well as enough reactive functional groups for ligand attachment. ${ }^{1,9}$ In this work, chitosan-based monoliths were prepared by a combination of freezing and lyophilization methods and further evaluated according to their morphological and mechanical properties. It is known that the macromolecular morphology of monoliths is influenced by the conditions employed during their preparation - in general, the freezing and lyophilization processes generate open pore microstructures with a high degree of interconnecting pores in the composite materials. Large pores and high interconnectivities contribute to high fluxes across the materials and faster bioseparation processes. ${ }^{15}$

Native monoliths prepared only with chitosan (CHT_N) present regular and spherical pores (data not shown); the addition of PVA facilitates the formation of monoliths (CP_N) with large and semi-spherical pores (Fig. 1A), while the copolymerization with GMA $\left(\mathrm{CG}_{-} \mathrm{N}\right)$ enables obtaining even larger and more elongated pores (Fig. 1B). In order to look deeper into the porous network prepared, analysis by mercury intrusion porosimetry was performed. The average pore size diameter for CHT_N monoliths is $17 \mu \mathrm{m}$, while those of $\mathrm{CP}_{-} \mathrm{N}$ and $\mathrm{CG} \_\mathrm{N}$ monoliths are $53 \pm 5$ and $123 \pm 5 \mu \mathrm{m}$, respectively (Table 1), which corroborate the conclusions taken from SEM image analysis. The porosity values are similar for all chitosanbased monoliths, varying between (70-75) $\pm 5 \%$, which was expected due to the constant temperature conditions employed during monolith preparation. Typically, the pore size decreases with the decrease of freezing temperature. ${ }^{15,16}$ During the freezing process, water ice crystals are formed and separate from the solutes which will be confined to the interstitial regions between ice crystals. Large ice crystal formation is expected in less viscous casting solutions and higher freezing temperatures, and the opposite is also true. ${ }^{16}$ In this work, chitosan-based casting solutions were frozen at $-80{ }^{\circ} \mathrm{C}$, a temperature at which a low average pore size diameter-between 20 and $100 \mu \mathrm{m}$ - is obtained. ${ }^{9,16}$ This average pore size diameter is within the range of interest for the purpose of the work. Concerning bioseparation applications, monoliths with large pores and high porosities are required to enable the fast permeation of cellular components and proteins present in crude samples. ${ }^{25}$ Therefore a delicate
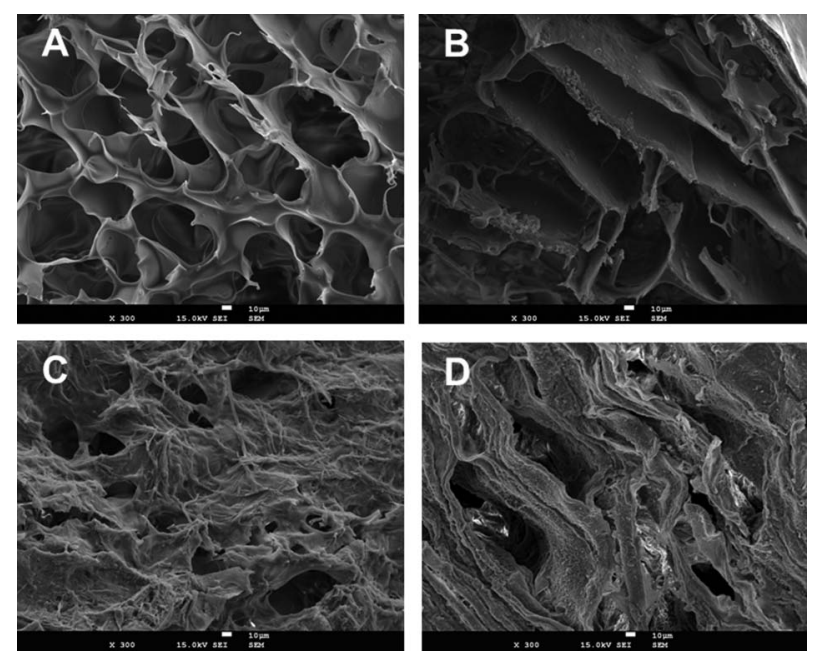

Fig. 1 SEM images of chitosan (CHT) based-monoliths before and after functionalization with the ligand 22/8: (A) $\mathrm{CP}_{-} \mathrm{N}$, native monolith prepared from chitosan and polyvinyl alcohol; (B) CG_N, native monolith prepared from chitosan and glycidyl methacrylate; (C) CP_22/8, functionalized CP monolith and (D) CG_22/8, functionalized CG monolith. All the images have a magnification of 300 and the scale bar in white indicates $10 \mu \mathrm{m}$.

balance between pore size diameter, porosity and surface area is needed during monolith design. If monoliths have larger pores $(\geqslant 150 \mu \mathrm{m})$ the surface area available for further functionalization decreases, leading to a low density of the affinity ligand. ${ }^{9,16,26}$ Also, a decrease of specific surface area with increasing average pore size diameter is expected. The monoliths inner surface area (total pore area) is in the range of values of similar 3D porous structures reported in the literature. ${ }^{25}$ The permeability and the compressive modulus of native chitosanbased monoliths are included in Table 1. The highest permeability value is registered to CG_N monolith, $390 \mathrm{~L} \mathrm{~m}^{-2} \mathrm{~h}^{-1}$ atm $^{-1}$, followed by $\mathrm{CP}_{-} \mathrm{N}$ and $\mathrm{CHT}_{-} \mathrm{N}$ monoliths with permeability values of 294 and $142 \mathrm{~L} \mathrm{~m}^{-2} \mathrm{~h}^{-1}$ atm $^{-1}$, respectively. These results indicate a clear concordance between the permeability of the materials and their morphological properties and also a good interconnectivity between the pores. The density of the dried and wet chitosan-based monoliths (Table 1), was calculated by measuring the weight and dimensions of the prepared materials. Dried native chitosan-based monoliths present similar values of density. Wet native monoliths also showed similar densities although 50 times greater than the dried ones due to their huge water uptake ability. The compressive mechanical properties were studied by uniaxial compression measurements also under dry and hydrated conditions. The compression modulus $(\mathrm{kPa})$, given by the slope of stress-strain curves, translates the material stiffness (Table 1). In general, a high compression modulus indicates a stiffer material. ${ }^{27}$ Native CHT-based monoliths present lower compression modulus values when compared to the functionalized materials. In more detail, CP_N monoliths at different stages, wet or dry, always present higher values of compression modulus than $\mathrm{CG}$ ones. The hydrated CG_N monolith exhibits a huge swelling and consequently becomes fragile, losing the initial integrity. These results are consistent with the morphological and mechanical

\section{(1)}

3 (1) 
Table 1 Morphological and mechanical characterization of chitosan-based monoliths before and after functionalization with ligand 22/8. All data was obtained from triplicated measurements

\begin{tabular}{|c|c|c|c|c|c|c|c|c|}
\hline \multirow[b]{2}{*}{ Monolith } & \multirow{2}{*}{$\begin{array}{l}\text { Average pore } \\
\text { size diameter }{ }^{a}(\mu \mathrm{m})\end{array}$} & \multirow{2}{*}{$\begin{array}{l}\text { Porosity }{ }^{a} \\
(\%)\end{array}$} & \multirow{2}{*}{$\begin{array}{l}\text { Surface Area } \\
\left(\mathrm{m}^{2} \mathrm{~g}^{-1} \text { monolith }\right)\end{array}$} & \multirow{2}{*}{$\begin{array}{l}\text { Permeability } \\
\left(\mathrm{L} m^{-2} \mathrm{~h}^{-1} \mathrm{~atm}^{-1}\right)\end{array}$} & \multicolumn{2}{|c|}{ Density $\times 10^{-3}\left(\mathrm{~g} \mathrm{~cm}^{-3}\right)$} & \multicolumn{2}{|c|}{ Compressive Modulus $(\mathrm{kPa})$} \\
\hline & & & & & Dry & Wet & Dry & Wet \\
\hline CP_N & $53 \pm 5$ & $70 \pm 5$ & $1.3 \pm 0.1$ & $294 \pm 15$ & $4 \pm 2$ & $165 \pm 10$ & $0.41 \pm 0.5$ & $0.2 \pm 5$ \\
\hline CP_22/8 & $45 \pm 5$ & $68 \pm 5$ & $2.3 \pm 0.2$ & $123 \pm 15$ & $3 \pm 2$ & $146 \pm 5$ & $14 \pm \overline{5}$ & $9 \pm 4$ \\
\hline CG_22/8 & $85 \pm 10$ & $60 \pm 10$ & $1.5 \pm 0.2$ & $323 \pm 10$ & $5 \pm 2$ & $131 \pm 10$ & $8 \pm 2$ & $4 \pm 2$ \\
\hline
\end{tabular}

${ }^{a}$ Determined for dried monoliths by mercury porosimetry analysis. ${ }^{b}$ n.a. The mechanical assay was impossible to perform due to the high swelling of $\mathrm{CG} \_\mathrm{N}$.

properties previously discussed-supports with lower average pore size diameter and porosity are more rigid and present higher compression modulus. It is also known that the compression modulus of porous structures prepared at higher freezing temperatures (e.g. -30 and $-20{ }^{\circ} \mathrm{C}$ ) are lower than those prepared at $-80{ }^{\circ} \mathrm{C}$, due to the smaller pore size attained at this temperature. $^{25}$ Other factors that can influence the support stiffness is the water absorption ability, and the proof of it is the dramatic decrease of mechanical properties observed for monoliths in the hydrated sate.

\subsection{Preparation and characterization of affinity chitosan-based monoliths}

Several methodologies for affinity monoliths activation and ligand coupling have been described by diverse authors.9,24 Herein the functionalization of chitosan monoliths with a triazine-based ligand (ligand 22/8) followed two different strategies. The first one was based on the optimized procedure for agarose ${ }^{5}$ and was also applied to cellulose membranes ${ }^{7}$ due to the similarity in the chemical composition of these supports, namely the high content of free hydroxyl groups.

Native chitosan-based monoliths were activated with epichlorohydrin in order to add epoxide functionality for subsequent amination. As this epoxyactivation procedure occurs through the reaction of epichlorohydrin with free $\mathrm{OH}$ groups, the density and availability of $\mathrm{OH}$ groups determine the extension of the epoxide functionality achieved. The epoxy activation yielded densities for CHT, CP and CG were $187 \pm 51$,

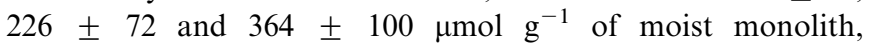
respectively. These epoxy densities are significantly higher than those reported in the literature for agarose $(50 \mu \mathrm{mol}$ of epoxy per gram of moist weight gel $)^{5}$ and for cellulose membranes $(130 \pm$ $10 \mu \mathrm{mol}$ of epoxy per gram of moist membrane). The second strategy consisted of the activation of native chitosan-based monoliths by argon (Ar) plasma treatment. Plasma treatment is a solvent free technique which allows the surface modification according to the gas and power applied. ${ }^{17}$ In this work, Ar plasma treatment introduced radicals onto the chitosan materials for subsequent reaction with 1,6-diaminohexane. The latter acts as a spacer $\operatorname{arm}^{3,5}$ between the surface of the epoxy or plasma activated chitosan-based monoliths and the small biomimetic ligand 22/8, contributing to an optimal interaction between the ligand and the target protein (Scheme 1)

The amination values achieved were significantly higher for all chitosan-based scaffolds activated by plasma treatment (Table 2). The maximum amount of amines introduced using epoxy activated chitosan-based monoliths was $364 \pm 50 \mu \mathrm{mol}$

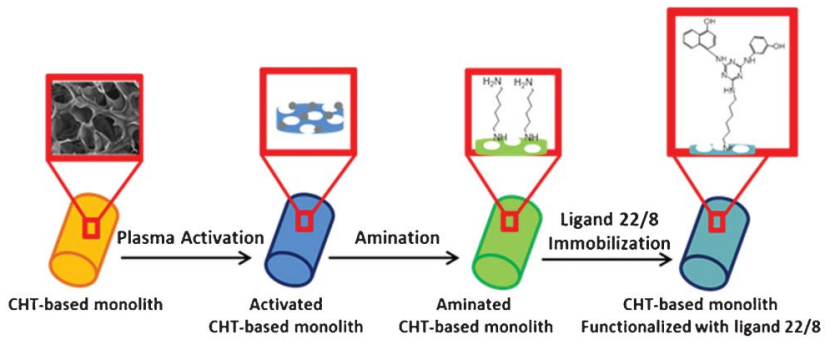

Scheme 1 Schematic showing the functionalization strategy of chitosanbased monoliths with ligand 22/8 using non-thermal plasma surface activation.

$\mathrm{g}^{-1}$ support. In marked contrast, using the new approach based on plasma surface activation this value increased almost 5-fold $\left(1747 \pm 47 \mu \mathrm{mol} \mathrm{g}^{-1}\right.$ support). Due to these remarkable yields of amination, chitosan-based monoliths activated by plasma treatment were subsequently coupled with ligand 22/8. This ligand was prepared following the procedure described by Lowe et al. ${ }^{5}$ and was immobilized onto the aminated chitosan-based monoliths still containing a labile chloride on the triazine ring for nucleophilic substitution. Different yields of ligand immobilization were obtained (Table 2), according to the monolith materials. Although the highest value of ligand immobilization was obtained for the CP monolith, $910 \pm 17 \mu \mathrm{mol} \mathrm{g}^{-1}$ support, however $\mathrm{CG}$ monolith also presented a very high functionalization ratio, $677 \pm 24 \mu \mathrm{mol} \mathrm{g}{ }^{-1}$ support. The different ligand densities on $\mathrm{CP}$ and $\mathrm{CG}$ monoliths can be related with the surface area available in each support. CP monoliths have a smaller pore size diameter and porosity than CG monoliths suggesting that $\mathrm{CP}$ supports have higher surface area available for further functionalization. These facts contributed to a decrease of possible active sites in CG monoliths and consequently to lower ligand density compared to the $\mathrm{CP}$ ones. In this work, the density of ligand 22/8 immobilized in chitosan-based monoliths was 10-fold the value reported for ligand 22/8 immobilized in agarose beads, ${ }^{5,6} 70$-fold on cellulose membranes, ${ }^{7}$ and less than 2 -fold on magnetic nanoparticles. ${ }^{8}$ It can also be noted that, in general, the density of immobilized ligand $22 / 8$ is quite high when compared to the values obtained for immobilized natural ligands. ${ }^{23,28}$ To the best of our knowledge, this is the first report on the preparation of affinity monoliths with such a high ligand density. After ligand 22/8 immobilization, the morphological and mechanical properties of chitosanbased monoliths were evaluated. SEM images represented in

(1) 
Table 2 Functionalization of monoliths with amine groups using either the traditional or the plasma activation routes and surface density of affinity ligand achieved by non-thermal plasma activation of the supports

\begin{tabular}{llll}
\hline Monolith & $\begin{array}{l}\text { Epoxy activation } \\
{\left[\mathrm{NH}_{2}\right]\left(\mu \mathrm{mol} \mathrm{g}{ }^{-1} \text { support }\right)}\end{array}$ & $\begin{array}{l}\text { Plasma activation } \\
{\left[\mathrm{NH}_{2}\right]\left(\mu \mathrm{mol} \mathrm{g}^{-1} \text { support }\right)}\end{array}$ & $\begin{array}{l}\text { Plasma activation } \\
\text { Ligand } 22 / 8 \text { immobilization }\left(\mu \mathrm{mol} \mathrm{g}^{-1} \text { support }\right)\end{array}$ \\
\hline $\mathrm{CP}$ & $226 \pm 72$ & $1747 \pm 47$ & $910 \pm 17$ \\
$\mathrm{CG}$ & $364 \pm 100$ & $906 \pm 246$ & $667 \pm 24$ \\
\hline
\end{tabular}

Fig. 1C and D show that the porous network and architecture

10 did not change significantly after the functionalization procedure proving the potential of the new strategy developed in this work. The average pore size diameter, porosity and surface area values obtained for affinity CP_22/8 and CG_22/8 monoliths registered in Table 1 were kept approximately within the combined experimental errors. Permeability values obtained for $\mathrm{CP}$ and CG monoliths decreased from 294 to $123 \mathrm{~L} \mathrm{~m}^{-2} \mathrm{~h}^{-1} \mathrm{~atm}^{-1}$ for CP_22/8, and from 390 to $323 \mathrm{~L} \mathrm{~m}^{-2} \mathrm{~h}^{-1}$ atm $^{-1}$ for $\mathrm{CG} \_22 / 8$ monoliths. The flow reduction can be explained by the presence of the affinity ligand which confers a hydrophobic character to 20 the supports. However, it should be noted that the permeability still shows the target values for separation processes whilst allowing enough residence time for the contact between the protein and the support. ${ }^{3}$ The apparent density of dried affinity monolithic supports did not change compared to the native ones at the same conditions, while wet monoliths showed a slight increase.

After functionalization, $\mathrm{CP} \_22 / 8$ and $\mathrm{CG} \_22 / 8$ registered a decrease in density values which can be also explained by the hydrophobic nature of ligand 22/8 leading to a reduction in the compressive modulus increased ( $\sim 10$-fold) for all monoliths after ligand coupling (refer to Table 1). The improvement of the monolith mechanical properties whether in dry or wet conditions was expected as the incorporation of a synthetic ligand confers rigidity and robustness to the monoliths.

Therefore, the sustainable functionalization strategy of the monoliths based on plasma activation and further ligand 22/8 coupling is able to keep most morphological properties of the native supports while improving their mechanical properties.

In order to evaluate the stability of the affinity monoliths at typical operating conditions used during purification processes, monoliths were incubated at several $\mathrm{pH}$ solutions (from $\mathrm{pH} 1$ to 12), corresponding to those employed in equilibration, elution, regeneration and cleaning-in-place of chromatographic matrices.

45 The amount of ligand released from the support was monitored (Fig. 2). The maximum amount of ligand 22/8 released from CP_22/8 and CG_22/8 was $12 \%$ and $7 \%$, after 4 and $2 \mathrm{~h}$ of incubation, respectively (Fig. $2 \mathrm{~A}$ and $\mathrm{C}$ ). In particular, at the $\mathrm{pH}$ conditions used in the binding and elution of antibodies from ligand 22/8 supports, $\mathrm{pH} 3$ and 8 respectively, the greatest amount of ligand leaching was observed after 2 and $4 \mathrm{~h}$, for CP_22/8 and CG_22/8. In general, the maximum time of monolith exposure to these conditions during a typical purification run is $30 \mathrm{~min}$, far below the threshold time for ligand leaching, which was only observed after $2 \mathrm{~h}$ of exposure. On the other hand, the highest loss of ligand from $\mathrm{CP} \_22 / 8$ and $\mathrm{CG}_{2}$ 22/ 8 occurs with sodium hydroxide solutions after 2 h (Fig. $2 \mathrm{~B}$ and D). Nevertheless the maximum contact time of each functionalized monolith at these harsh conditions (CIP conditions) is

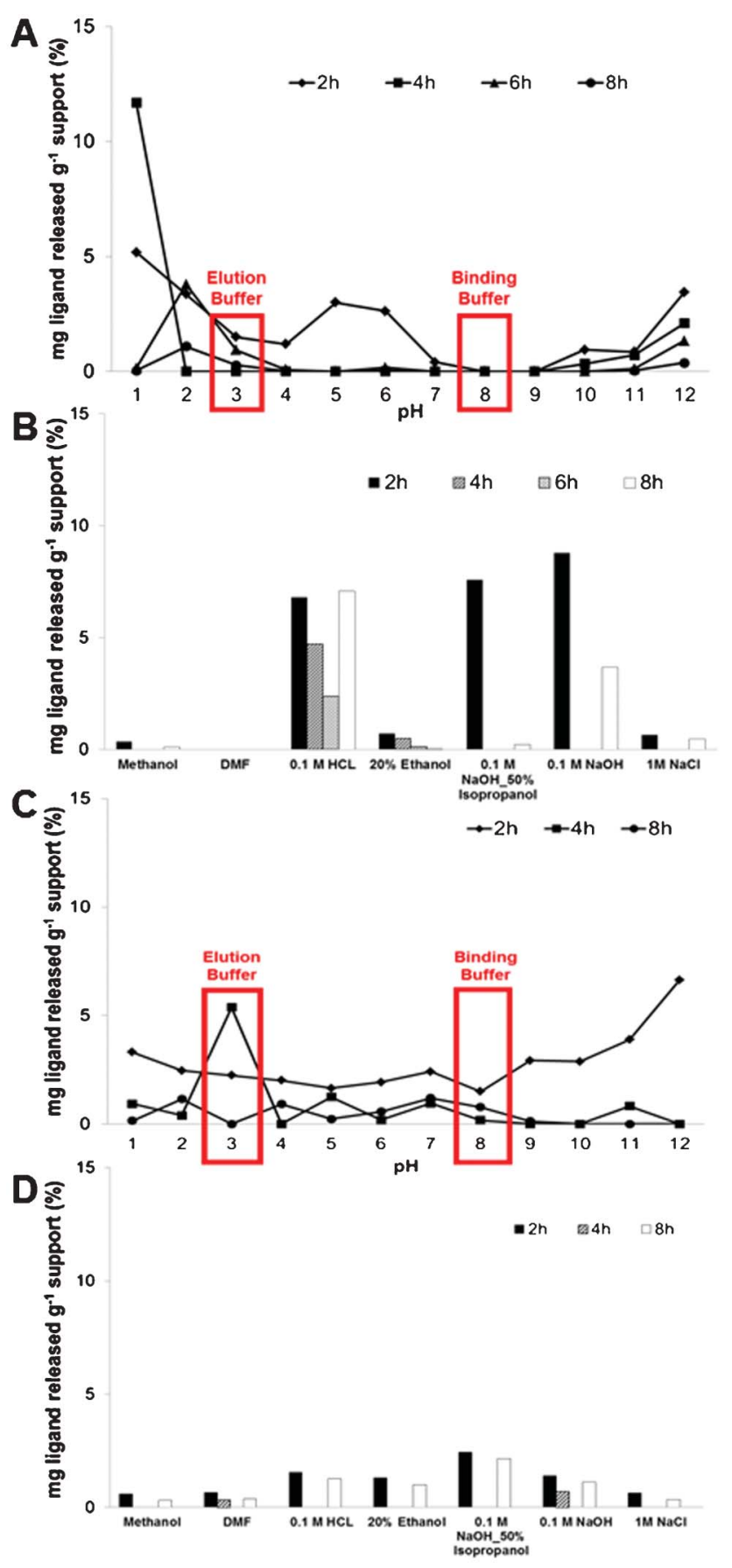

10

Fig. 2 Stability evaluation of CP_22/8 (A and B) and CG_22/8 (C and D) monoliths immersed over $12 \mathrm{~h}$ in solutions typically used during cleaning-in-place (CIP) procedures, including solutions with $\mathrm{pH}$ values between 1 and 12. All data was obtained from duplicated measurements with errors of \pm 5 . 
about $10-20 \mathrm{~min}$, the time at which no ligand release was registered.

\subsection{Evaluation of affinity monoliths for antibody purification}

To evaluate the affinity constants for $\mathrm{hIgG}$ and BSA on native and functionalized chitosan-based monoliths, static partition equilibrium measurements were performed in duplicate. To attain the equilibrium between proteins and affinity supports, ${ }^{10}$ partition equilibrium studies were performed in a batch system over $12 \mathrm{~h}$, varying the protein concentration.

The experimental data was fitted using a LangmuirFreundlich isotherm that is the indicated model for porous structures with heterogeneous morphology. Different affinity constants $\left(K_{\mathrm{a}}\right)$, theoretical maximum capacity $\left(Q_{\max }\right)$ and Langmuir-Freundlich coefficients $(n)$ were obtained (Fig. 3) with an error of $\pm 0.5, \pm 40.0$ and \pm 0.1 , respectively. The affinity monoliths always presented higher values of $K_{\mathrm{a}}$ and $Q_{\max }$ (14 and 3-fold, respectively) when compared to the native ones. The CG_22/8 monolith registered the highest value of $K_{\mathrm{a}}$ and $Q_{\max }, 4.0 \times 10^{4} \mathrm{M}^{-1}$ and $590 \mathrm{mg} \mathrm{hIgG} \mathrm{g}^{-1}$ support, respectively. Calculated $K_{\mathrm{a}}$ values exhibit the same order of magnitude usually obtained for similar affinity devices fitted with Langmuir-Freundlich isotherm. ${ }^{27,28,31}$ In addition, $K_{\mathrm{a}}$ values obtained for $\mathrm{CP} \_22 / 8$ and $\mathrm{CG}_{2} 22 / 8$ are an order of magnitude lower than the $K_{\mathrm{a}}$ values reported for agarose, ${ }^{5}$ magnetic nanoparticles ${ }^{8}$ and cellulose membranes ${ }^{7}$ functionalized with ligand 22/8 and fitted with a Langmuir isotherm model. It should be remarked that values of $K_{\mathrm{a}}$ in a range between $10^{4}$ and $10^{6} \mathrm{M}^{-1}$ indicate a medium affinity interaction, considered optimal for bioseparation processes while facilitating protein recovery. The values of $Q_{\max }$ for $\mathrm{CP} \_22 / 8$ and $\mathrm{CG}_{2} 22 / 8$, 475 and $590 \mathrm{mg} \mathrm{hIgG} \mathrm{g}^{-1}$ support respectively, are 2-fold those for agarose ${ }^{5}$ and magnetic particles ${ }^{8}$ functionalized with ligand $22 / 8$, and very close to the one obtained for cellulose membrane. ${ }^{7}$ Values of Langmuir-Freundlich coefficients higher than $1(n>1)$ were registered for all functionalized monoliths suggesting a positive cooperativity in binding (attractive forces due to lateral interactions) and a heterogeneous nature of protein adsorption.
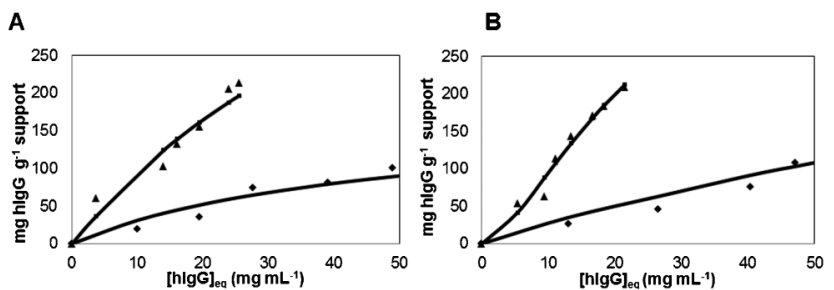

C

\begin{tabular}{|c|c|c|c|c|c|c|c|c|}
\hline \multirow[t]{2}{*}{ Monolith } & \multicolumn{2}{|c|}{$K_{\mathrm{a}} /\left(10^{4} \mathrm{M}^{-1}\right)$} & \multicolumn{2}{|c|}{$\begin{array}{c}Q_{\max } \\
\text { (mg hlgG } \mathrm{g}^{-1} \text { support) }\end{array}$} & \multicolumn{2}{|c|}{$\mathrm{n}$} & \multicolumn{2}{|c|}{$\mathbf{R}^{2}$} \\
\hline & $C P$ & CG & $C P$ & CG & CP & CG & CP & CG \\
\hline Native & 0.08 & 0.3 & 270 & 185 & 1.2 & 0.96 & 0.95 & 0.97 \\
\hline $22 / 8$ & 1.1 & 4.0 & 475 & 590 & 1.5 & 1.05 & 0.97 & 0.96 \\
\hline
\end{tabular}

Fig. 3 Langmuir-Freundlich adsorption isotherms for (A) CP and (B) CG monoliths: $(\diamond)$ native and $(\boldsymbol{\Delta})$ functionalized. (C) summarizes the estimated parameters of the Langmuir-Freundlich isotherms and standard errors for $\mathrm{CP}$ and $\mathrm{CG}$ monoliths before and after functionalization with ligand $22 / 8$.
The cooperativity depends on the macromolecular nature and multiple functional groups, which usually results in multiple interactions. ${ }^{27,28}$ It should be noted that the same adsorption assays were performed with bovine serum albumin (BSA), a model contaminant protein of antibodies in serum and cell culture supernatants and none of the tested isotherms could fit the experimental data. This result indicates a nonspecific adsorption of BSA.

The dynamic binding capacity of a stationary phase is one of the most critical factors to evaluate its chromatographic performance. To assess the mass transfer and dynamic binding properties of the affinity monoliths, breakthrough curves of purified human $\mathrm{IgG}$ were measured in duplicates for two flow rates (Fig. 4), as the binding capacities and elution efficiency of supports are affected by the residence time on the monolithic chromatographic column.

Both supports, CP_22/8 and CG_22/8, duplicated the binding and elution capacities when the flow rate decreased from 2 to 1 $\mathrm{mL} \min ^{-1}$ (Fig. 4). The estimated binding capacities for CP_22/8 and CG_22/8 were $57 \pm 10$ and $15 \pm 5 \mathrm{mg} \mathrm{hIgG} \mathrm{g}^{-1}$ support respectively, when using a flow rate of $2 \mathrm{~mL} \mathrm{~min}^{-1}$ and $110 \pm 15$ and $26 \pm 8 \mathrm{mg} \mathrm{hIgG} \mathrm{g}^{-1}$ support for a flow rate of $1 \mathrm{~mL} \mathrm{~min}^{-1}$, respectively. The elution capacity for $\mathrm{CP} \_22 / 8$ and $\mathrm{CG}_{2} 22 / 8$ increased from 40 to $90 \pm 5 \%$ and from 30 to $60 \pm 5 \%$ when the flow rate decreased from 2 to $1 \mathrm{~mL} \mathrm{~min}^{-1}$.
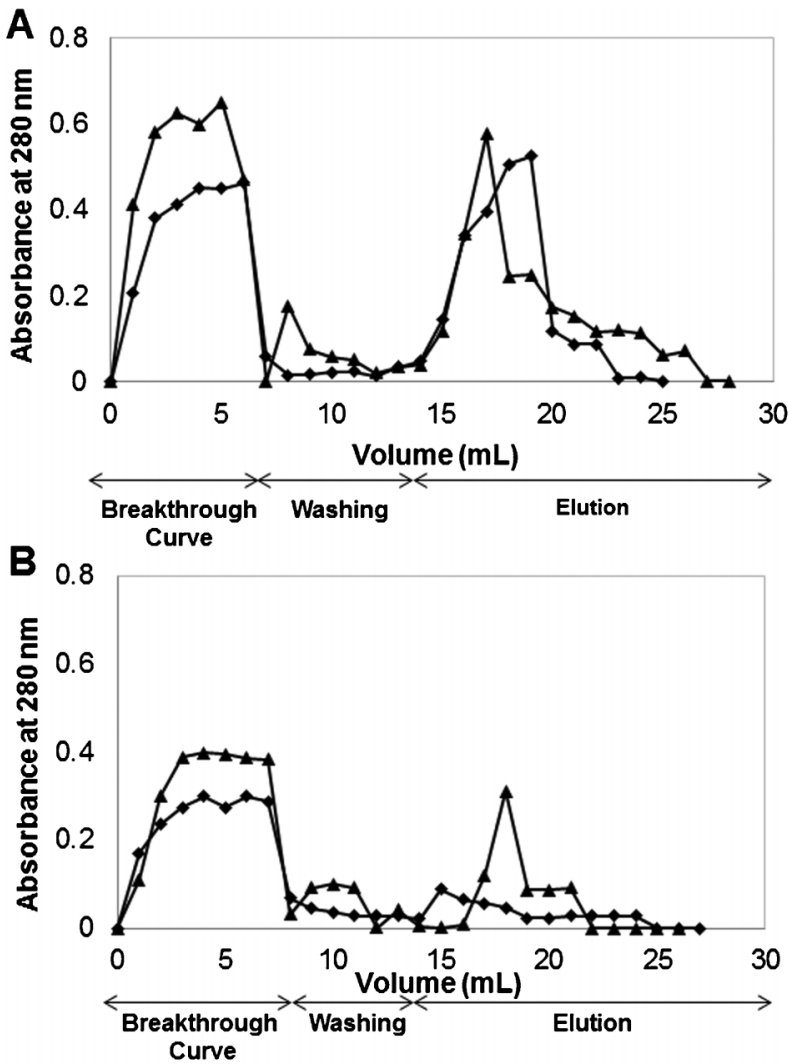

Fig. 4 Breakthrough profiles for human IgG upon (A) CP_22/8 and

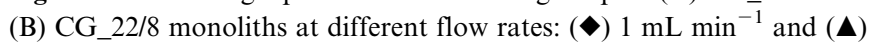
$2 \mathrm{~mL} \min ^{-1}$. 


\subsection{Optimization of an affinity monolith for antibody recovery}

Due to the promising morphological, mechanical and physicochemical properties, high stability at different $\mathrm{pH}$ conditions and high static and dynamic binding capacities towards human IgG, CP monoliths were selected for the optimization of $\mathrm{IgG}$ purification process. In order to evaluate and enhance the efficiency of affinity CP monoliths for antibody capture and recovery, three consecutive chromatographic cycles and a fourth one after monolith autoclaving (After_AC) were performed in duplicates at two different flow rates, 2 and $1 \mathrm{~mL} \mathrm{~min}^{-1}$. BSA, the model contaminant, was used as a control in the same experiments in order to evaluate the selectivity and affinity of CP_N and CP_22/8 towards hIgG. CP monoliths exhibited different performances on capturing and eluting $\mathrm{hIgG}$ and BSA (Fig. 5 and Fig. 6).
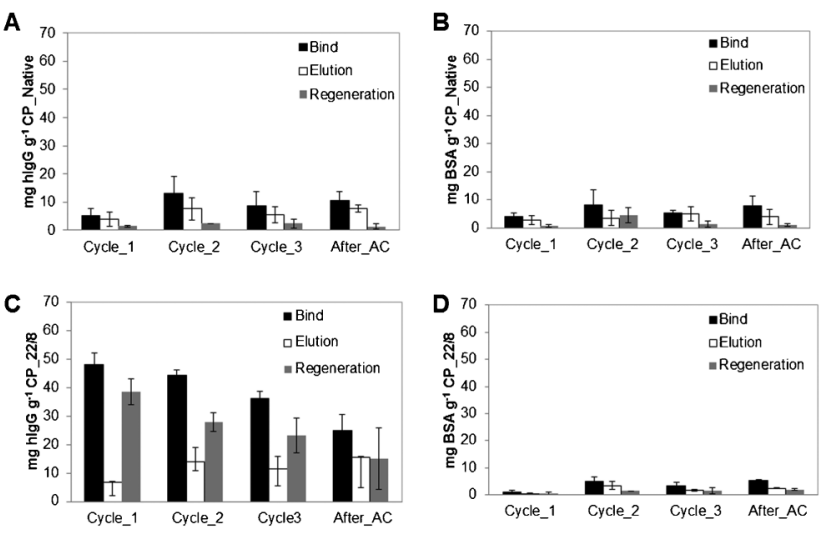

Fig. 5 Evaluation of chromatographic performance for (A, B) native and $(\mathrm{C}, \mathrm{D})$ functionalized $\mathrm{CP}$ monoliths using pure $\mathrm{IgG}$ and BSA solutions, respectively. The chromatographic procedures (bind, elution and regeneration steps) were performed consecutively along four cycles at a flow rate of $2 \mathrm{~mL} \mathrm{~min}^{-1}$. The last cycle was performed after autoclaving (After_AC).
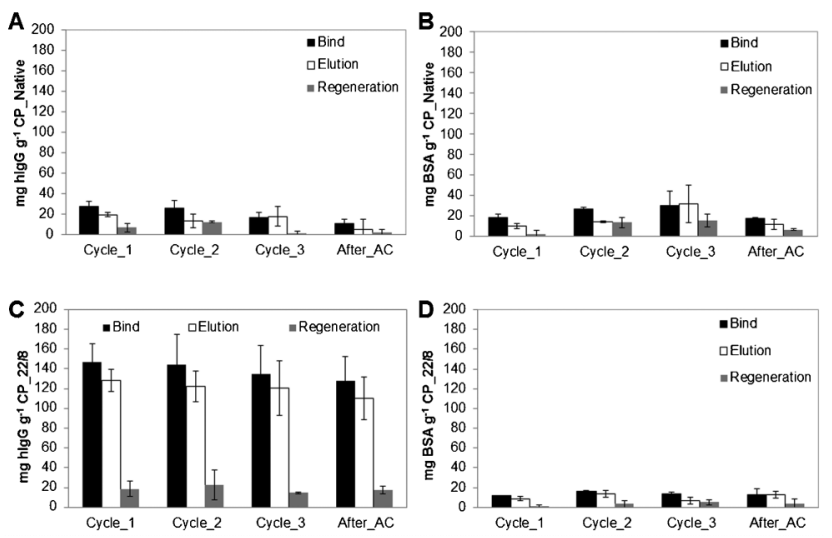

Fig. 6 Evaluation of chromatographic performance for (A, B) native and $(\mathrm{C}, \mathrm{D})$ functionalized $\mathrm{CP}$ monoliths using pure $\mathrm{IgG}$ and BSA solutions, respectively. The chromatographic procedures (bind, elution and regeneration steps) were performed consecutively along four cycles at a flow rate of $1 \mathrm{~mL} \min ^{-1}$. The last cycle was performed after autoclaving (After_AC).
In detail, Fig. 5A and $\mathrm{B}$ show that $\mathrm{CP} \_\mathrm{N}$ has approximately the same low capacity to capture and elute hIgG and BSA over the four cycles, suggesting residual non-specific interactions between the support and the proteins. In marked contrast, the functionalized CP_22/8 monoliths showed a substantial increase in binding and elution capacity towards hIgG (Fig. 5C) while only a negligible amount of BSA was retained (Fig. 5 D). Although presenting affinity and selectivity to hIgG molecule, the affinity monoliths lost their capacity for re-utilization, especially after autoclaving which is translated by a slight decrease in the bind and elution values. At these operational conditions, CP_22/8 loses around $20 \%$ of capacity after 3 chromatographic cycles, and 50\% after autoclaving (Fig. 5C).

On the other hand, only $25 \%$ of the captured hIgG was recovered in the elution step, whereas $75 \%$ was washed during the regeneration step under extremely harsh conditions deleterious for the protein. Subsequent assays, performed at a lower flow rate $\left(1 \mathrm{~mL} \mathrm{~min}^{-1}\right)$, allowed an increase of the residence time and the achievement of affinity equilibrium between the attached ligand and the receptor in the solution (Fig. 6). Comparing the chromatographic runs showed in Fig. $5 \mathrm{C}$ and $6 \mathrm{C}$, it is clear that CP_22/8 exhibited a great improvement in the binding and elution of $\mathrm{hIgG}$ as only reducing the flow rate to a half led to an over 3-fold increase of captured and eluted hIgG, $150 \pm 10$ and $135 \pm 5 \mathrm{mg} \mathrm{g}^{-1}$ support, respectively. Consequently, the amount of $\mathrm{hIgG}$ recovered during the regeneration step was significantly reduced, $10 \pm 5 \mathrm{mg} \mathrm{g}^{-1}$ support. The bind and elution capacity of the monoliths was maintained with a slight decrease after autoclaving (a decrease of 15\%). This remarkable performance of monoliths for recovering $\mathrm{IgG}$ using the flow rate of $1 \mathrm{~mL} \mathrm{~min}^{-1}$ led to results that depart considerably from the reported outcomes obtained with affinity membranes, particles and other monoliths used in antibody purification. $5,7,8,26,29$

The most critical part of the study was to evaluate the direct capture of monoclonal antibodies (Mabs) from a non-clarified homogenate. Fig. 7 presents the chromatogram of non-clarified crude extract of Mabs using CP_N and CP_22/8 monoliths (A) as well as the SDS-PAGE gel, ${ }^{32}$ revealed using Coomassie Blue $\mathrm{R}-250$, obtained from the recovered samples during the chromatographic experiment (B). The chromatogram obtained from crude extract sample shows that $\mathrm{CP}_{-} \mathrm{N}$ did not capture any protein (Fig. 7A) while the affinity monolith CP_22/8 captured $61 \pm 10 \%$ of Mabs from a mammalian crude extract with initially $1.3 \mathrm{mg}$ of total protein per millilitre and eluted $80 \pm 8 \%$ of bounded protein. When considering the purity of the samples, the flow-through (3) and the wash (4) contained contaminant proteins and antibody, while the elution fractions $(5,6)$ showed a high purity of the antibody (estimated as $98 \%$ by ImageJ analysis). These results confirm the efficacy of $\mathrm{CP} \_22 / 8$ in capturing and eluting Mabs with great purity from a real crude extract.

\section{Conclusions}

Herein we report for the first time the preparation of chitosanbased monoliths by combining a freeze drying process with surface activation by plasma treatment to modify them with a robust biomimetic affinity ligand, previously reported as an artificial Protein A for antibody purification. It was demonstrated 

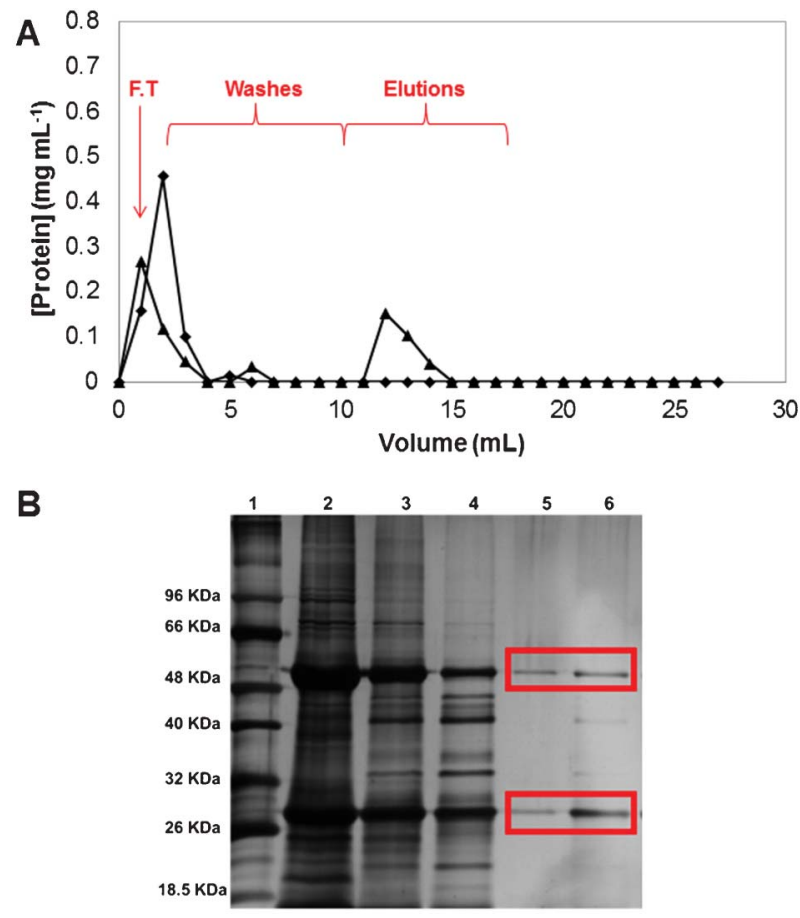

F. 7 Chromatogram of Mabs purification from crude extract using (A) CP monoliths: $(\diamond)$ native and $(\boldsymbol{\Delta})$ functionalized, at a flow rate of 1 $\mathrm{mL} \mathrm{min}^{-1}$. The fractions collected included the flowthrough (F.T.) followed by the washing and elution steps. The acrylamide gel from SDSPAGE performed with the fractions collected during the Mabs purification (B): lane 1 corresponds to the calibration proteins, lane 2 represents the loading, lane 3 is the flowthrough, lane 4 corresponds to the first wash (phosphate buffer $(50 \mathrm{~mm}, \mathrm{pH} 8.0)$ ), and lane 5 and lane 6 are the first and second elution fractions (sodium citrate buffer $(50 \mathrm{~mm}$, $\mathrm{pH} 3.0)$ ).

35 that the morphological and mechanical properties of monoliths can be tuned according to the polymer blend composition, while the new strategy to couple the affinity ligand was able to improve the chemical and physical stability towards the final application. The functionalization strategy based on plasma activation proved to be safer and more efficient than traditional activation procedures which involve multiple steps and innumerous organic solvents. The main practical advantages of the strategy described are that by fast and solventless plasma activation of different substrates, a direct procedure of functionalization could be applied leading to robust affinity monoliths able to selectively capture and elute antibodies even from homogenate crude extracts. Preliminary results of monoclonal antibody (Mabs) capture from a non-clarified homogenate suggested that CP_22/8 is able to recover Mabs with $98 \%$ purity.

A straightforward extension of the materials and functionalization approach based on plasma technology herein described can be envisaged for the production of polymeric devices with different geometries and properties, and for the conjugation of a wide range of biological and artificial receptors. The properties of affinity polymeric devices can be tuned towards different applications in addition to the example here presented. For instance, they can find applications on the pre-concentration and solid-phase extraction of compounds, on organo- and biocatalysis processes, on analytical and biosensing systems, on tissue engineering and as supports for cellular growth and expansion.

\section{Experimental}

\subsection{Materials}

Ammonium peroxodisulphate (APS, purity $\geqslant 98 \%$ ), citric acid (purity $\geqslant 99 \%$ ), disodium hydrogen phosphate monodibasic (pro analysis), disodium hydrogen phosphate dibasic (pro analysis), disodium tetraborate, ethanol absolute and sodium citrate dihydrate were purchased from Merck. Isopropanol and sodium bicarbonate were purchased from Riedel-de-Haën. Acetone (purity $\geqslant 99 \%$ ), and ethyl acetate were supplied by Roth. Acetic acid (purity $\geqslant 99 \%$ ), Aminocaproic acid, 3-aminophenol, 4-amino-1-naphthol hydrochloride, cyanuric chloride (purity $\geqslant 98 \%$ ), 1,6-hexanodiamine (purity $\geqslant 98 \%$ ), N,N-dimethylformamide (DMF), dimethylsulfoxide (DMSO), glycine, ninhydrin, potassium cyanide, pyridine, sodium hydroxide (purity $\geqslant 99 \%$ ) were purchased from Sigma Aldrich. Chitosan (75 85\% deacetylated, medium molecular weight), poly(vinyl alcohol) (purity $\approx 99 \%$ ), N,N-methylenebisacrylamide (MBAm, purity $\geqslant 85 \%$ ), N,N, $\mathrm{N}^{\prime}, \mathrm{N}^{\prime}$-tetramethylethylenediamine (TEMED, purity $\approx 99 \%$ ), bicinchoninic acid (BCA) kit, bovine serum albumin (BSA) (purity $\geqslant 98 \%$ ) were supplied by Sigma Aldrich. Human IgG was purchased by Gammanorm (purity $\geqslant 99 \%$ ).

\subsection{Monoliths preparation}

Chitosan-based monoliths were prepared blending different ratios of chitosan $(0-100 \%$ (wt per wt)) with PVA $(0-50 \%)$ and GMA $(10 \%)$ in acetic acid aqueous solution ( $1 \% \mathrm{v}$ per v). The crosslinker agent, MBA, was also added ( $2 \%$ (wt per wt)) and different casting solutions were placed in glass tubes and stirred until homogeneous casting solutions were obtained. After the initiator and catalyst, TEMED $(23 \mu \mathrm{L})$ and APS $(40 \mu \mathrm{L})$, were added to promote the crosslinking process. The crosslinking process occurred at $0{ }^{\circ} \mathrm{C}$ during $30 \mathrm{~min}$ under stirring. The casting solutions were frozen at $-80{ }^{\circ} \mathrm{C}$ during $12 \mathrm{~h}$ and were lyophilized (Telstar cryodos-50) until dry. ${ }^{25,26}$

\subsection{Monoliths characterization}

Chitosan-based monoliths morphology was investigated using scanning electron microscopy (SEM) in Hitachi S 2400 equipment with an accelerating voltage set to $15 \mathrm{kV}$. The samples were frozen and fractured in liquid nitrogen for cross-sectional analysis and gold coated before analysis. Chitosan-based monoliths porosity, average pore size diameter and surface area were determined by mercury porosimetry (Micromeritics, autopore IV). Water fluxes were determined at $25{ }^{\circ} \mathrm{C}$ and by varying the applied hydrostatic pressure (within $0-0.4 \mathrm{MPa}$ ) using a stainless steel high-pressure cell (with an effective volume of $1.2 \mathrm{~cm}^{3}$ ). At least three measurements of distilled water flux were performed for each monolith. The permeability $\left(L_{\mathrm{p}}\right)$ of chitosan-based monoliths was obtained by the slope of linear relation between flux $(F)$ and pressure $(p)$, and is given by Darcy Law, ${ }^{7}$ represented by:

$$
F=L p \times \Delta p
$$


The wet and dry densities were determined through the ratio of wet weight as well as dry weight of the chitosan-based monoliths with respect to their volume. The apparent density in $\mathrm{g} \mathrm{cm}^{-3}$ was calculated by the equation below as described by Tripathi et al. ${ }^{14}$

$$
\rho=\frac{w}{\pi} \times \frac{D^{2}}{4} \times H
$$

where $w$ is the weight of monolith sample in grams, $D$ is the diameter of the sample in $\mathrm{cm}$ and $H$ is the thickness of the sample in $\mathrm{cm}$.

Uniaxial compression was used to determine the mechanical properties of the monoliths using tensile testing equipment (MINIMAT firmware v.3.1) at room temperature. Samples were prepared in a cylindrical shape (10 $\mathrm{mm}$ in diameter thickness). The length between clamps was set at $5 \mathrm{~mm}$, the speed set to $01 \mathrm{~mm} \mathrm{m^{-1 }}$, a full scale load of $20 \mathrm{~N}$ and maximum extension of $90 \mathrm{~mm}$ was used. The compression modulus was calculated from the slope of the linear portion of the stress-strain curve: ${ }^{7}$

$$
\begin{aligned}
& \text { Stress }=\sigma=\frac{F}{A} \\
& \text { Strain }=\varepsilon=\frac{\Delta l}{L}
\end{aligned}
$$

where $F$ is the applied force, $A$ the cross sectional area, $\Delta l$ is the change in length and $L$ is the length between clamps. All samples were tested in dry state at room temperature.

\subsection{Monolith functionalization}

The chitosan-based monoliths followed two different activation strategies for ligand 22/8 immobilization. The first one involved the introduction of reactive epoxy groups on monoliths by epoxy activation. $\mathrm{CP}$ and $\mathrm{CG}$ monoliths were covered with distilled water $(10 \mathrm{~mL}), \mathrm{NaOH}(72 \mu \mathrm{L}, 0.1 \mathrm{M})$ and epichlorohydrin $(0.83 \mathrm{~mL})$ and then incubated for $3 \mathrm{~h}$ at $35^{\circ} \mathrm{C}$ on a rotary shaker (140 rpm). After incubation, the epoxy-activated chitosan-based monoliths were washed with distilled water $(200 \mathrm{~mL})$. The epoxy activation content was determined by adding sodium thiosulfate $(3 \mathrm{~mL}, 1.3 \mathrm{M})$ to 1 gram of epoxy-activated chitosan-based monoliths and incubating them at room temperature for $20 \mathrm{~min}$. This mixture was neutralized with $\mathrm{HCl}(0.1 \mathrm{M})$ and the amount of $\mathrm{HCl}$ was registered. The volume of $\mathrm{HCl}$ added corresponded to the amount of hydroxyl ions released. The second strategy (Scheme 1) involved the use of plasma treatment which was carried out in a radio frequency plasma reactor (Plasma system FEMTO, version 5). Native chitosan-based monoliths were introduced in a plasma chamber which was thoroughly purged with a continuous flow of argon to reduce trace amounts of air and moisture. During the treatment, the argon flow was adjusted in order to keep a constant pressure of 0.3 Torr inside the chamber. A power of $60 \mathrm{~W}$ was applied over $5 \mathrm{~min}$. At the end of the experiment the plasma chamber was ventilated and the activated samples were immediately introduced in an aqueous solution of hexane-1,6-diamine to be aminated. Activated chitosan-based monoliths reacted with an excess of hexane-1,6diamine in water for $24 \mathrm{~h}$ at $45^{\circ} \mathrm{C}$, and then thoroughly washed with water in order to remove residues of hexane-1,6-diamine which did not react. The extent of amination was determined using the Kaiser test. This test is a colorimetric assay to quantify free amine groups and is based on the reaction of ninhydrin with primary amines, which gives a characteristic dark blue color. To perform the Kaiser test, each following reagents i) $80 \%$ crystalline phenol in ethanol (w/v), ii) $2 \%$ aqueous solution of potassium cyanide $(0.001 \mathrm{M})$ in pyridine $(\mathrm{v} / \mathrm{v})$ and iii) $5 \%$ ninhydrin in ethanol $(\mathrm{w} / \mathrm{v})$ were added $(50 \mu \mathrm{l}$ of each one) to the aminated chitosan-based monolith samples $(1 \mathrm{~mL})$. The samples were then placed in a water-bath at $100{ }^{\circ} \mathrm{C}$ during $5 \mathrm{~min}$. The calibration curve was represented by standard solutions of

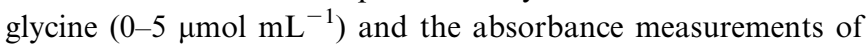
the samples (diluted $1: 18$ ) were performed at $560 \mathrm{~nm}$. For ligand 22/8 immobilization, an excess of ligand 22/8 (3 equiv. to the amination content, $530 \mu \mathrm{mol}, 200 \mathrm{mg}$ ), was added to the aminated chitosan-based monolith samples (approximately $60 \mathrm{mg}$ ) in water-DMF (1:2). The volume of solvent used was sufficient to cover the chitosan-based monoliths, and the solution was incubated on a rotary shaker $(140 \mathrm{rpm})$ for $72 \mathrm{~h}$ at $85{ }^{\circ} \mathrm{C}$. The synthesis of ligand $22 / 8$ followed the procedure described by Teng et al. ${ }^{5}$ and Barroso et.al. ${ }^{7}$ The synthesis of ligand $22 / 8$ was confirmed by ${ }^{1} \mathrm{H}$ and C-NMR and FT-IR. Functionalized chitosan-based monolith samples were then washed with water-DMF (1:2) until the absorbance at $270 \mathrm{~nm}$ was zero.

In order to assure a complete exclusion of non-absorbed ligands into and onto chitosan-based monoliths, functionalized samples were introduced in a Varian column (a reservoir with $3 \mathrm{~mL}$ of capacity) and were submitted to several washes with water-DMF (1:2) and to clean-in-place-procedure. The cleanin-place-procedure consisted of washing functionalized chitosanbased monoliths with $\mathrm{NaOH}$ (1 M) until the absorbance at $270 \mathrm{~nm}$ be zero, with water $(10 \mathrm{~mL})$, then with regeneration buffer $(\mathrm{NaOH} \quad 0.1 \mathrm{M}$ in $30 \%$ of isopropanol) until the absorbance at $270 \mathrm{~nm}$ be zero, and finally, again with distilled water $(10 \mathrm{~mL})$. The functionalized chitosan-based monoliths were equilibrated with sodium phosphate buffer $(50 \mathrm{mM}, \mathrm{pH}$ $8.0)$ and sodium citrate buffer $(50 \mathrm{mM}, \mathrm{pH} 3.0)$ until the absorbance at $270 \mathrm{~nm}$ be zero. The extinction coefficient of ligand 22/8 was determined at its maximum absorbance wavelength $\left(\varepsilon_{270}=10.72 \mathrm{~L} \mathrm{~g}^{-1} \mathrm{~cm}^{-1}\right)$, respectively. The ligand $22 / 8$ density was determined by subtracting the amount of ligand contained in all the washing liquors from the initial ligand used in the immobilization step. The chitosan-based monoliths containing ligand 22/8 were characterized in terms of morphological and mechanical properties as referred previously.

\subsection{Static partition equilibrium experiments}

Partition equilibrium experiments were performed in a batch system as described by Barroso et al. ${ }^{7}$ The adsorption of $\mathrm{hIgG}$ and BSA on the chitosan-based monoliths was investigated using a sample of native and functionalized chitosan-based $(10 \mathrm{mg})$ monoliths varying the concentration of hIgG and BSA (0.0$\left.45 \mathrm{mg} \mathrm{mL}{ }^{-1}, 400 \mu \mathrm{L}\right)$ in phosphate buffer (50 mM, pH 8.0) solutions. All experiments were conducted in duplicates at $25^{\circ} \mathrm{C}$, at a stirring rate of $200 \mathrm{rpm}$ during $12 \mathrm{~h}$. At the end of this period, the native and functionalized chitosan-based monoliths were removed from the medium. The amount of adsorbed hIgG and BSA was determined by measuring the initial and final 
concentrations of $\mathrm{hIgG}$ within the adsorption medium. A calibration curve was prepared using hIgG and BSA in phosphate buffer solutions (50 mM, pH 8.0) (0.0-45 mg $\left.\mathrm{mL}^{-1}\right)$. The concentration of protein was measured at $280 \mathrm{~nm}$ on a microplate reader (Tecan Infinite F200, filter, $\lambda=280 \mathrm{~nm}$ ). The adsorption phenomenon followed the Langmuir-Freundlich $\operatorname{model}^{27,28}$ and it was represented by:

$$
q=\frac{Q_{\mathrm{m}} \times(C)^{n}}{K_{\mathrm{d}}+(C)^{n}}
$$

where $K_{\mathrm{d}}$ is the apparent dissociation constant (M) that includes contributions from ligand binding to support, $Q_{\mathrm{m}}$ is the maximum binding capacity ( $\mathrm{mg}$ protein $\mathrm{g}^{-1}$ support), $C$ is the concentration of protein in the liquid at the equilibrium (M) and $n$ represents the Langmuir-Freundlich coefficient.

\subsection{Frontal Analysis-breakthrough curves and binding capacity}

The dynamic loading capacity of the packed columns with native 20 and functionalized chitosan-based monoliths was determined using frontal analysis according with the equation ${ }^{33}$ below.

$$
Q=\frac{V_{\mathrm{e}}}{[\text { Protein }]_{\text {plateau }}}
$$

Where $Q$ corresponds to the estimated adsorbent capacity and $V_{\mathrm{e}}$ corresponds to the elution volume.

This technique consisted in loading hIgG and BSA solutions ( $\left.8 \mathrm{~mL}, 0.5 \mathrm{mg} \mathrm{mL}^{-1}\right)$ in sodium phosphate buffer $(50 \mathrm{mM}, \mathrm{pH}$ 8.0) through the equilibrated monolithic packed columns at different flow rates, 1 and $2 \mathrm{~mL} \min ^{-1}$ until the protein concentration of the output and input streams were identical. Then, packed monolithic columns were washed with phosphate buffer $(50 \mathrm{mM}, \mathrm{pH} 8.0)$ and the bound protein was eluted with sodium citrate buffer ( $50 \mathrm{mM}, \mathrm{pH} 3.0)$. Each collected milliliter during loading, washing and elution steps were analyzed by absorbance at $280 \mathrm{~nm}$, using a microplate reader, in order to estimate the amount of protein bounded and eluted.

\subsection{Chromatographic experiments}

In order to estimate the capacity of functionalized chitosanbased monoliths, Varian columns (with a capacity of $3 \mathrm{~mL}$ and an effective volume of $1.2 \mathrm{~cm}^{3}$ ) were packed with these polymeric affinity structures. The columns were connected to a peristaltic pump using rubber tubing in order to allow flow control. The affinity capturing experiments were performed in a step-wise adsorption-desorption process by switching eluents at room temperature and at atmospheric pressure. Packed columns with functionalized chitosan-based monoliths were loaded with $1 \mathrm{~mL}$ of hIgG and BSA solution $\left(5 \mathrm{mg} \mathrm{mL}^{-1}\right)$ in order to estimate the capacity of the columns for each protein. Then, columns were washed with sodium phosphate buffer $(50 \mathrm{mM}, \mathrm{pH} 8.0)$ until the absorbance measured at $280 \mathrm{~nm}$ reached $\leqslant 0.005$, in order to remove all the protein physically adsorbed. The bound protein was eluted and recovered with sodium citrate buffer $(50 \mathrm{mM}, \mathrm{pH}$ 3.0). Packed columns with functionalized chitosan-based monoliths were then regenerated as described above in order to be reused. These chromatographic experiments were repeated during 3 cycles and one more after auto-claving in order to evaluate the column capacity over time. The total amount of IgG bound, eluted and regenerated from the chitosan-based monoliths was initially determined by absorbance measured at $280 \mathrm{~nm}$ and by the BCA (microplate reader assay). As the results were consistent (data not shown) only absorbance measured at $280 \mathrm{~nm}$ was further used for protein quantification.

\subsection{Purification of monoclonal antibodies from mammalian crude extracts}

In order to evaluate the possibility to capture directly antibodies from non-clarified crude extracts, packed columns with native and functionalized CP monoliths were loaded with a mammalian crude extract solution $(1 \mathrm{~mL}, 1.3 \mathrm{mg}$ of total protein per milliliter). After crude extract loading, packed columns were washed with the sodium phosphate buffer $(15 \mathrm{~mL}, 50 \mathrm{mM}, \mathrm{pH}$ 8.0) until the absorbance measured at $280 \mathrm{~nm}$ reached $\leqslant 0.005$ and the bound protein was after eluted and recovered with sodium citrate buffer (50 mM, pH 3.0). All collected samples were analyzed by the BCA assay in order to quantify the amount of total protein bound and eluted from the solid support. The BCA assay consists in adding the BCA working reagent $(200 \mu \mathrm{L})$ to the samples $(25 \mu \mathrm{L})$. The microplates were incubated in the dark for $30 \mathrm{~min}$ at $37{ }^{\circ} \mathrm{C}$. A standard curve was determined for each assay (200-1000 $\mu \mathrm{g} \mathrm{mL}^{-1}$ ). SDS-PAGE was performed on acrylamide gel $(12.5 \%)$ in Tris-Glycine buffer system $\mathrm{pH} 8.3$. Electrophoresis apparatus (from BIO-RAD) was connected with power supply at $120 \mathrm{~V}, 190 \mathrm{~mA}$ for $1 \mathrm{~h}$. The staining solution was prepared by adding $1 \mathrm{~g}$ of Coomassie Blue R-250, $15 \mathrm{ml}$ of glacial acetic acid, $90 \mathrm{ml}$ of methanol, and deionized water until $200 \mathrm{ml}$.

\section{Acknowledgements}

The authors would like to thank the financial support from Fundação para a Ciência e Tecnologia, Portugal, through contracts MIT-Pt/BS-CTRM/0051/2008, PTDC/EBB-BIO/ 102163/2008 and PTDC/EBB-BIO/098961/2008 and doctoral grant SFRH/BD/62475/2009 (T. B.), Bioengineering Systems Focus Area, Fundação Calouste Gulbenkian, FEDER and FSE. We wish to thank the Analytical Services Laboratory of REQUIMTE for the characterization of materials. Authors are also thankful to Lonza Biologics, UK (Dr Richard Alldread) and the Animal Cell Technology Unit of ITQB-UNL/IBET (Dr Paula M Alves and Dr Ana Teixeira) for providing the cell culture bulks of antibodies.

\section{References}

1 (a) D. Low, R. O'Leary and N. S. Pujar, J. Chromatogr., B: Anal. Technol. Biomed. Life Sci., 2007, 848, 48; (b) M. Fuentes, C. Mateo, R. Fernández-Lafuente and J. M. Guisán, Biomacromolecules, 2006, 7, 540 .

2 (a) H. Alkan, N. Bereli, Z. Baysal and A. Denizli, Biochem. Eng. J., 2009, 45, 201; (b) Y. Goto, R. Matsuno, T. Konno, M. Takai and K. Ishihara, Biomacromolecules, 2008, 9, 828.

3 K. Mondal and M. N. Gupta, Biomol. Eng., 2006, 23, 59.

4 A. Jungbauer and R. Hahn, J. Chromatogr., A, 2008, 1184, 62.

5 S. F. Teng, K. Sproule, A. Husain and C. R. Lowe, J. Chromatogr., Biomed. Appl., 2000, 740, 1.

6 S. F. Teng, K. Sproule, A. Husain and C. R. Lowe, J. Mol. Recognit., 1999, 12, 67.

,


7 T. Barroso, M. Temtem, A. Husain, A. Aguiar-Ricardo and A. C. A. Roque, J. Membr. Sci., 2010, 348, 224.

8 I. L. Batalha, A. Hussain and A. C. A. Roque, J. Mol. Recognit, 2010, 23, 462.

9 (a) R. Mallik and D. S. Hage, J. Sep. Sci., 2006, 29, 1686; (b) M. J. Hortigüela, I. Aranaz, M. C. M. Gutieürrez and L. Del Monte, Biomacromolecules, 2011, 12, 179.

10 G. Bayramoglu, A. U. Senel and M. Y. Arica, Sep. Purif. Technol., 2006, 50, 229.

11 A. Jungbauer and R. Hahn, J. Chromatogr., A, 2008, 1184, 62.

12 J. L. Williams, Catal. Today, 2001, 69, 3.

13 C. Peskoller, R. Niessner and M. Seidel, J. Chromatogr., A, 2009, 1216, 3794.

14 (a) F. M. Plieva, H. Kirsebom and B. Mattiasson, J. Sep. Sci., 2011, 34, 2164; (b) A. Tripathi and A. Kumar, Macromol. Biosci., 2011, 11, 22.

15 T. Nge, M. Nogi, H. Yano and J. Sugiyama, Cellulose, 2010, 17, 349.

16 S. Deville, Materials, 2010, 3, 1913.

17 (a) T. Desmet, R. Morent, N. Geyter, C. Leys, E. Schacht and P. Dubruel, Biomacromolecules, 2009, 10, 2351; (b) J. Cho, F. S. Denes and R. B. Timmons, Chem. Mater., 2006, 18, 2989.

18 M. Schulze, A. Yanguas-Gil, A. Von Keudell and P. Awakowicz, J. Phys. D: Appl. Phys., 2008, 41, 065206.

19 F. J. ÓBrien, B. A. Harley, Y. V. Yannas and L. Gibson, Biomaterials, 2006, 25, 1077

20 J. J. A. Barry, M. M. C. G. Silva, K. M. Shakesheff, S. M. Howdle and M. R. Alexander, Adv. Funct. Mater., 2005, 15, 1134.

21 T. Barroso, R. Viveiros, M. Temtem, T. Casimiro, A. M. Botelho do Rego and A. Aguiar-Ricardo, ACS Macro Lett., 2012, 1, 356.

22 (a) S.-W. Choi, J. Xie and Y. Xia, Adv. Mater., 2009, 21, 2997; (b) P. Sabrina, K. Tommeras, K. M. Varum and K. Ostgaard,
Biomacromolecules, 2001, 2, 1313; (c) Y. Cheng, X. Luo, G. F. Payne and G. W. Rubloff, J. Mater. Chem., 2012, 22, 7659.

23 Y. C. Wei, S. M. Hudson, J. M. Mayer and D. L. Kaplan, J. Polym. Sci., Part A: Polym. Chem., 1992, 30, 2187.

24 (a) M. Temtem, T. Barroso, T. Casimiro, J. F. Mano and A. AguiarRicardo, J. Supercrit. Fluids, 2012, 66, 398; (b) M. Temtem, L. M. C. Silva, P. Z. Andrade, F. dos Santos, C. L. da Silva, J. M. S. Cabral, M. M. Abecasis and A. Aguiar-Ricardo, J. Supercrit. Fluids, 2009, 48, 269.

25 (a) P. Arvidsson, F. M. Plieve, V. I. Lozinsky, I. Y. Galaev and B. Mattiasson, J. Chromatogr., A, 2003, 986, 275; (b) N. Kathuria, A. Tripathi, K. K. Kar and A. Kumar, Acta Biomater., 2009, 5, 406; (c) A. Wang, Q. Ao, W. Cao, M. Yu, Q. He, L. Kong, L. Zhang, Y. Gong and X. Zhang, J. Biomed. Mater. Res., Part A, 2006, 1, 36.

26 (a) D. Josic and A. Buchacher, J. Biochem. Biophys. Methods, 2011, 49, 153; (b) A. Bronshtein, N. Aharonson, A. Turnianski and M. Altstein, Chem. Mater., 2000, 12, 2050.

27 C-F. Dai, C.-J. Weng, P.-R. Li and J.-M. Yeh, Polym. Degrad. Stab., 2010, 95, 600.

28 C. Boi, J. Chromatogr., B: Anal. Technol. Biomed. Life Sci., 2007, 848, 19.

29 L. C. L.Aquino, E. A. Miranda, I. S. Duarte, P. T. V. Rosa and S. M. A. Bueno, Braz. J. Chem. Eng., 2003, $20,3$.

30 R. Wongchuphan, B. T. Tey, W. S. Tan, F. S. Taip, S. M. M. Kamal and T. C. Ling, Biochem. Eng. J., 2009, 45, 232.

31 L. G. Berruex, R. Freitag and T. B. Tennikova, J. Pharm. Biomed. Anal., 2000, 24, 95.

32 (a) R. J. Carreira, F. M. Cordeiro, A. J. Moro, M. G. Rivas, R. RialOtero, E. M. Gaspar, I. Moura and J. L. Capelo, J. Chromatogr., A, 2007, 1153, 291; (b) V. Neuhoff, N. Arold, D. Taube and W. Ehrhardt, Electrophoresis, 1988, 9, 255-262.

33 D. J. Winzor, J. Biochem. Biophys. Methods, 2001, 49, 99. 